\title{
Expectancy for Success and Perceived Stress In Relation To Parenting among Teenagers
}

\author{
Dr. M. K. Mathew ${ }^{1}$, Mrs. Chinchu Rani Vincent ${ }^{2}$
}

Keywords: Expectancy, Success, Perceived Stress, Parenting, Teenagers

The child's first and foremost developmental context happens within the family. Hence family plays a major role in the development of a child, where in the parents have the majority of responsibilities in bringing up of the child. Hence parenting is an art of cherishing a child right through its life (James, A. 2003). There are different parenting styles adopted by parents according to circumstances. Whatever may be the style of parenting; there will be effects on the child's overall development. The parenting styles are based on the entire specific behavioural patterns that influence the mental developments of children.

Parents play an important role in working with their teenage children in attaining successes and minimizing risks. At the same time, parental bond helps the teens to face today's difficult decisions and serious risks to their wellbeing. Today attending college and schools is the dominant activity for teens and they come across many stressful situations. Despite many improvements in teen's standards of living, level of education and opportunities for advancement, today's teens still face many threats and challenges. Many of these threats are behavioral such as drinking, smoking, drug-use, premature sexual activity, suicide and violence.

Teens undergo a number of developmental adjustments including biological, cognitive, emotional and social changes on their way to becoming adults. While there are many factors that influence the incidence of these risks, these behaviours can be significantly affected by teens themselves as well as by the involvement of their families or society at large to help overcome these risks and enable teens to reach their full potential. Decisions teens make are critical for their present and future wellbeing. Educational choices play a potentially large role in teens future career choices and success. As teens weigh these decisions, parents have an enormous potential to influence their teenagers behaviour. A close relationship with parents is also associated with higher grades and greater intention to go to college.

\footnotetext{
${ }^{1}$ Department of Behaviour Science, Mahatma Gandhi University, Kottayam, Kerala

${ }^{2}$ Research Scholar, Mahatma Gandhi University, Kottayam, Kerala

(C) 2015 I M Mathew, C Vincent; licensee IJIP. This is an Open Access Research distributed under the terms of the Creative Commons Attribution License (http://creativecommons.org/licenses/by/2.0), which permits unrestricted use, distribution, and reproduction in any Medium, provided the original work is properly cited.
} 
During the early 1960s, psychologist Diana Baumrind conducted a study on more than 100 preschool-age children (Baumrind, 1967). Using naturalistic observation, parental interviews and other research methods she suggested that the majority ofparents display one of three different parenting styles. Further research by Maccoby and Martin also suggested the addition of a fourth parenting style (Maccoby, E.E, 1983) generally known as the parenting patterns. They are namely authoritarian parenting, authoritative parenting, permissive parenting and uninvolved parenting. Each of these patterns follows certain styles and behavioural pattern of parenting. These styles influence the overall emotional and psychological growth of children. These patterns differ in disciplinary measures, warmth and nurturance tactics, communication methods and control and maturity levels.

Parents are the major influence in their children's lives. Thus their perception of how children think, and should be raised is crucial in determining the child'sbehaviour.(Omitiri,T.2012).Studies reveal a correlation between parenting styles and school competence, delinquency, stress, success, violence, sexual activity, antisocial behaviour, alcohol and substance abuse, depression, anxiety, and self-perception.Different parenting styles have different impact on child development.Factors such as a heavy school work load, concerns over examination grades, peer pressure or family conflicts may all have been continuous stressors to students and to worsen this condition, inappropriate parenting behaviours can elevate the stress level among children. Parenting behaviours tend to have an impact on children's stress level and may further affect children's psychosocial development.

A Parenting Scale (P Scale) was developed by R.L. Bharadwaj and H. Sharma. In this scale of parenting it is intended to measure perceptions of the individual/child about one's own feelings as to how he/she was brought up by his/her parents on eight dichotomous modes of parenting (perceived parenting).(Ramey, S.L. 2002) The final form of this scale has eight different modes of parenting as mentioned below:
A. Rejection Vs Acceptance
B. Carelessness Vs protection
C. Neglect Vs Indulgence
D. Utopian Expectations Vs Realism
E. Lenient standard Vs Moralism
F. Freedom Vs Discipline
G. Faulty Role Expectations Vs Realistic Role Expectation
H. Marital conflict Vs Marital adjustment

Expectancy for success is defined as a children's belief about how well they will do on an upcoming task. Beliefs about ability refer to children's evaluations of their competence in different areas. Researchers proposed that children's achievement performance, persistence, and choice of achievement tasks are most directly predicted by their expectancies for success on those tasks.(Omitiri,T.2012). Children's expectancies and values themselves are most directly 


\section{Expectancy for Success and Perceived Stress In Relation To Parenting among Teenagers}

determined by other achievement-related beliefs, including children's achievement goal and selfschemata, and their task-specific beliefs. Children's interpretations of their past performance, and their perceptions of socializers' attitudes and expectation.

Parenting styles are associated with different child outcomes and for example authoritative style is generally linked to positive behaviour such as strong self-esteem and self-competence. Thus it can be found to have a great correlation between the variables perceived stress, expectancy for success in relation to different parenting styles in teenagers.

\section{RELEVANCE OF THE STUDY}

Human life completes its journey through various stages and one of the most vital stages is teenage. Teenage is the period of transition from childhood to adulthood and plays a decisive role in the formation of either a pro-social or an antisocial adult. Because parents provide a critical environment for children's development, the influence of parenting processes and the quality of parent-child relationships has to be a key focus of family research.

When we come to this world we are completely dependent upon others and learn gradually to be independent. In India, the teenagers do most of the work themselves but the final decision regarding various domains of life is taken by their parents. Stress level are far higher than they think is healthy and their average reported stress exceeds that of adults. Different parenting styles do exerts its own effects on teenage behaviours. This difference in parent child relationship can have profound effect on teenager's expectancy for success and perseverance of stress in their life. However, little is known about the view of teenager's view of different parenting. Changing family contexts are likely to exert influences on parenting practises. Insight into teenager's experience of parenting practices is therefore both invaluable and imperative given the significant impact that parenting practices exert on outcomes and teenagers psychological wellbeing in general.

This study focuses on analysing the correlation between the variables perceived stress and expectancy for success in relation to different parenting styles among teenagers.

\section{OBJECTIVES}

The study focussed on the following objective to achieve desired results based on which the same can be extended to other settings.

- To study and analyse how teenagers' perception of the effects of different parenting practices on their lives.

- To explore the level of parent-child relationship and its psychological aspects.

- To analyse expectancy for Success and Perceived Stress in relation to how teenagers perceive parenting. 


\section{METHODOLOGY}

The sample size of the study, methods used for data collection, procedures used during the administration and the statistical analysis used for the interpretation of the result are discussed below.

\section{Sample}

The study was conducted among 31 participants belonging to the age group 13-19. Convenient sampling method was used to collect data. The data was collected from different schools in Kottayam and Idukki district.

\section{Measures}

The tools used in this study were Parenting style (P scale) scale, developed by Dr. R.L. Bharadwaj Perceived Stress Scale (PSS) developed by Prof. Sheldon Cohen and Generalized Expectancy for Success Scale (GESS) developed by W.D Hale and L.R Fiedler. Parenting style (P scale) scale consists of 40 questions, Perceived Stress Scale consisted of 10 questions and Generalized Expectancy for Success Scale consists 30 questions. Reliability and validity of the tools were established.

\section{Scoring}

The procedure for scoring is done with a scoring key given in manuals.

\section{$\underline{\text { Parenting Scale (P Scale) }}$}

a. The scoring of this parenting scale is of quantitative type and is based on 5 point scale as suggested by Likert. The scoring and determination of mothering and fathering as well as parenting is complex one and the following things are to be kept in mind at the time of scoring the scale.

b. Each item of the scale is to be scored from upper to lower in terms of 1,2,3,4,and 5.the scoring of item number $4,11,18,25$ and 32 will be in the reverse order.

c. The obtained scores are to be transferred on the last page at the space provided for both the parents and are to be added vertically to determine the raw score for mothering and fathering separately for different modes of parenting

d. The obtained raw scores for different modes of parenting are to be transferred into 'Z' score.

e. The total of ' $Z$ 'scores for each mode of parenting in realtion to both the parents shall be treated as parenting scores.

\section{Perceived Stress Scale (PSS)}

The PSS consists of multiple choice questions. Items include choice on a 5-point agreement scale. The points corresponding to each level of the scale are marked with 
boldfaced brackets: [0], [1], [2], [3], or [4]. Items number 4, 5, 7, and 8 require reverse coding, which is reflected in their corresponding brackets. To compute the total assessment score, sum all scale items. Total scores will range from 0 to 40 .

\section{Generalized Expectancy for Success Scale (GESS)}

Generalized Expectancy for Success Scale (GESS) consists of 30 items based on a Likert scale (5= highly probable, 1 =highly improbable). Items 1 , 2, 4, 6, 7, 8, 14,15,17,18, 24, 27, and 28 are scored in reverse. All items have the same opening phrase: "In the future I expect that I will ...." Subjects were required to indicate to a different ending on each item, each of which represents a belief of success or failure within the future. Higher scores on this scale indicate subjects' greater expectancy for success in the future and greater motivation to face difficult challenges.

\section{Procedure}

Individual administration was used. Participants were asked to sit comfortably and a good rapport was established with the general brief talk with them. They were told to answer each question with a tick mark in the place corresponding to the one which they consider suitable. They were told that there is no right or wrong answers and there is no fixed time to finish the test. But ordinarily they can take test 15-20 minutes for completing the test. It wasensured that the answers would remain confidential. As soon as they finished their work, test materials were collected.

\section{Statistical Analysis}

Descriptive and Inferential statistical method was used to analyse the data collected to understand the pattern of data points and the tools that are to be used. Based on the descriptive, the most suitable inferential statistics were selected and the results interpreted thereof.

\section{RESULTS, DISCUSSION AND CONCLUSION}

Table 4.1 shows the mean value score obtained for parenting style, perceived stress and expectancy for success.

\begin{tabular}{|l|l|}
\hline Parenting style & 735.2 \\
\hline Perceived stress & 17.42 \\
\hline Expectancy for success & 95.32 \\
\hline
\end{tabular}


Table 4.2 shows the correlation values obtained for parenting and perceived stress and for parenting and expectancy for success.

\begin{tabular}{|l|l|}
\hline$\gamma 1$ & -0.01 \\
\hline$\gamma 2$ & +0.0157 \\
\hline
\end{tabular}

$\gamma 1$ - Correlation value of the variables parenting styles and perceived stress.

$\gamma_{2}$-Correlation value of the variables parenting styles and expectancy for success.

\section{RESULTS}

From the above table 4.1 the mean value of parenting style is 735.2, mean value of perceived stress is 17.42 and mean value of expectancy for success is 95.32 . From the table 4.2 the value of correlation between parenting styles and perceived stress is -0.01 and the value of correlation between parenting styles and expectancy for success is +0.0157 .

\section{DISCUSSION}

The aim of the study was to analyse how parenting relates to expectancy for success and perceived stress of the subject. A parenting style is psychological construct representing standard strategies that parents use in their child rearing. Difference in parenting strategies has relation with how teenagers perceive stress, their expectancy for success etc.

The inferential statistical method used to analyse the data is correlation analysis. Correlation coefficient is the statistical value that helps us to know whether there exists a positive or negative relation between the perceived stress and parenting style and secondly, parenting style and expectancy for success.

From the table 4.2, theCorrelation value obtained for parenting and perceived stress depicts that there is only a very low negative correlation between those two variables. The obtained correlation value between parenting and expectancy for success depicts a low positive correlation between these variables.

From the table 4.2, it is seen that there is a negative correlation between parenting and perceived stress. The higher score in parenting scale depicts that the parents are perceived to be high in acceptance, moralism and discipline by the teenagers. Parental acceptance implies an attitude of love for the child and brings a positive attitude towards the teenager's idea, worthiness and capability of oneself. Thus for teenagers whose perception score of her/his parents on the dichotomous modes of parenting is high is seen to be having less perceived stress. And for teenagers, who perceive their parents to be neglecting and careless, scored less in parenting scores and high in perceived stress. 


\section{Expectancy for Success and Perceived Stress In Relation To Parenting among Teenagers}

From table 4.2 it shows that there exist a positive correlation between parenting and expectancy for success. It was seen that the respondents who were scored with high parenting score had high expectancy for success in their life. It shows the significance effect of effective parenting in our lives. Instead of pressing the children to come up with high success in each step in their lives a caring, responsible parent who is at the same time authoritative can contribute so much to the integral growth and development of an individual. Since teen age is a period of great transition and change parents who are the role models and guiding stars certainly can lead and guide their children to efficient and effective personalities.

\section{CONCLUSION}

From the above result and discussion, it is found that there exists a negative correlation between parenting and perceived stress and also there exists a positive correlation between parenting and expectancy for success among teenagers. Thus it is pertinent to note that the parenting plays a critical role in the upbringing of the offspring where a positive expectancy can result a vibrant society and in turn will help in developing a just and proud nation.

\section{REFERENCE}

Chopra, Rita, and Poonam Nangru. "A Study of Family Relationship in Relation to Emotional Intelligence." (2013).

Kumar, Arun, Mandeep Sharma, and DeeptiHooda. "Perceived parenting style as a predictor of hope among adolescents." Journal of the Indian Academy of Applied Psychology 38.1 (2012): 174-178.

Murray, Aisling. "The relationship of parenting style to academic achievement in middle childhood." The Irish Journal of Psychology 33.4 (2012): 137-152.

Raya, Antonio F., et al. "Parenting Style and Parenting Practices in Disabled Children and its Relationship with Academic Competence and Behaviour Problems." Procedia-Social and Behavioral Sciences 89 (2013): 702-709.

SHAHIMI, Farnaz, Patrick HEAVEN, and Joseph CIARROCHI. "The Interrelations among the Perception of Parental Styles and Psychological Well-Being in Adolescence: A Longitudinal Study.” Iranian Journal of Public Health 42.6 (2013): 570-580 